\title{
BMJ Open Influence of combined exposure to perceived risk at work and unstable employment on self-rated health: a comparison of two cross-sectional surveys in Europe and Korea
}

\author{
Seong-Sik Cho, ${ }^{1}$ Domyung Paek, ${ }^{2}$ Mo-Yeol Kang (i) ${ }^{3}$
}

To cite: Cho S-S, Paek D, Kang M-Y. Influence of combined exposure to perceived risk at work and unstable employment on self-rated health: a comparison of two cross-sectional surveys in Europe and Korea. BMJ Open 2020;10:e032380. doi:10.1136/ bmjopen-2019-032380

- Prepublication history and additional material for this paper are available online. To view these files, please visit the journal online (http://dx.doi. org/10.1136/bmjopen-2019032380).

Received 17 June 2019 Revised 02 December 2019 Accepted 10 December 2019

Check for updates

(c) Author(s) (or their employer(s)) 2020. Re-use permitted under CC BY-NC. No commercial re-use. See rights and permissions. Published by BMJ.

${ }^{1}$ Department of Occupational and Environmental medicine, Dong-A University College of Medicine, Busan, Republic of Korea

${ }^{2}$ School of Public Health, Seoul National University, Seoul, Republic of Korea

${ }^{3}$ Department of Occupational and Environmental Medicine, College of Medicine, The Catholic University of Korea, Seoul, Republic of Korea

Correspondence to Professor Mo-Yeol Kang; snaptoon@naver.com

\section{ABSTRACT}

Objectives The purpose of this study was to investigate the combined effect of exposure to perceived risk at work and unstable employment on self-rated health in both Korea and the European Union.

Design Cross-sectional study.

Setting We conducted the analyses using employees data from the third Korean Working Conditions Survey (KWCS) conducted in 2011 and the fifth European Working Conditions Survey (EWCS) conducted in 2010.

Participants Employees of the third KWCS and the fifth EWCS from 35 European countries were the participants of the study.

Primary outcome measures Employment status was divided into two categories: stable and unstable employment. Perceived risk regarding safety and health at work were assessed. Primary health outcomes were poor or moderate self-rated health. Exposures and health status were assessed via a questionnaire.

Results Among Korean employees, the OR of poor selfrated health was 2.00 (95\% Cl: 1.80 to 2.22) for those with perceived risk at work, $1.18(95 \% \mathrm{Cl}: 1.09$ to 1.28$)$ for those with unstable employment and 3.22 (95\% Cl: 2.72 to 3.81 ) for those with both perceived risk at work and unstable employment. Relative excess risk due to interaction (RERI) was 1.03 (95\% Cl: 0.48 to 1.58). Among European employees, the $\mathrm{OR}$ for poor self-rated health was 3.20 (95\% Cl: 2.93 to 3.49$)$ for those with perceived risk at work, 1.04 (95\% Cl: 0.97 to 1.13) for those with unstable employment and 3.41 (95\% Cl: 2.93 to 3.98 ) for those with both perceived risk at work and unstable employment. The RERI was 0.18 ( $95 \% \mathrm{Cl}$ : -0.36 to 0.71 ).

Conclusions Among Korean employees, a supra-additive interaction between perceived risk at work and unstable employment on poor self-rated health was observed. Conversely, a supra-additive interaction was not observed among European employees.

\section{INTRODUCTION}

Today, Korea still suffers from traditional industrial accidents and acute industrial intoxication. Although Korea has legal provisions prohibiting subcontracting and outsourcing of hazardous work, dangerous
Strengths and limitations of this study

- Our sample included a large number of workers from the general working population, allowing us to study a non-selective population, which has been shown to be crucial.

- As we compared representative data from Korea and European Union (EU) countries, surveyed using almost identical methodologies and survey questionnaires, it was possible to present result of Korea in parallel with that of the EU.

- Owing to its cross-sectional nature, the study could not establish a causal relationship between exposure and health outcome.

- The measurement of risk at work and health status was subjective and could be due to information bias.

and harmful jobs are increasingly being carried out by temporary workers. According to a report on fatal industrial accidents in the shipbuilding industry, the majority of fatal accidents occurred among workers with unstable employment. ${ }^{1}$ Despite limited systematic research on the difference in hazard exposure between employees with different employment status, ${ }^{2}$ short reports in newspapers on fatal injury occurrence among at-risk workers might reflect the inequalities across occupations and employment status.

Differences in exposure to hazardous conditions between regular workers and temporary workers in the same occupation highlight an important ethical issue. This deviates from the principle of equity and requires social efforts such as strict legal regulations on subcontracting or outsourcing hazardous work. Previous studies have reported the harmful effects of precarious or unstable employment on workers' health. ${ }^{3-5}$ Moreover, existing literature identifies a variety of potential moderators ${ }^{6}$ including occupational type 
(manual or non-manual), gender, personal characteristics, psychosocial work characteristics, social support, length of time spent in a precarious labour market position and union membership. In addition, it is well known that social factors such as employment protection laws, availability and amount of unemployment benefits, availability of jobs and active labour market policies can also influence the health-related consequences of job insecurity. ${ }^{7}$ However, the combined effects of unstable employment and perceived risk at work have rarely been studied. If working under unstable employment and dangerous working conditions simultaneously is more harmful due to the interaction between the two concurrent exposures, greater social efforts should be made to improve conditions surrounding these workers. It is also necessary to examine whether this interaction unique to Korea, where workers have been unfairly treated, or if a similar interaction exists in other industrialised countries.

A comparative study on health equality across countries provides insights into this question. ${ }^{8}{ }^{9}$ Improved social structure including the welfare system in each country, as well as the relationship between employers and employees, can change the negative perception of hazardous working conditions. ${ }^{10} 11$

Therefore, the aim of this study is to examine whether there is a difference in the combined effect of unstable employment and perceived risk at work on self-rated health between Korea and European countries.

\section{METHOD}

\section{Study subjects}

We used data from the third Korean Working Conditions Survey (KWCS) conducted in 2011, and the fifth European Working Conditions Survey (EWCS) conducted in 2010. These were nationally representative interview surveys which included questions relating to workers' socioeconomic data, workplace environment and social and occupational health. The fifth EWCS comprises data from 35 European countries with 43816 participants. The third Korean Working Conditions Survey (KWCS), which was based on the EWCS, was conducted by the Korea Occupational Safety and Health Agency. Total sample size of the KWCS was 50033 participants (unweighted sample size $=50032$ ), and the sample size of employees was 35904 (unweighted sample size $=29711$ ). Total sample size of the EWCS was 43816 (unweighted sample size $=43816$ ), and the sample size of employees was 35078 (unweighted sample size $=35181$ ). Self-employed people with or without employees and other types of employment were excluded from the analysis. The EWCS and KWCS assess the distribution of work-related risk factors to establish occupational safety policies. All study variables were assessed with the questionnaire. The surveys were conducted by trained interviewers through face-to-face interviews. To ensure comparability, the KWCS questionnaire was developed based on a translation of the questionnaire of the EWCS. The KWCS used a representative sample, only including the economically active population aged over 15 years in South Korea. ${ }^{12}$ Informed consent was obtained from all participants in both surveys, and detailed information about these surveys was made available on the following websites: http://www.eurofound.europa.eu/working/ surveys/ for the EWCS and http://www.kosha.or.kr/jsp/ kwcs/ for the KWCS.

\section{Sampling and survey weighting}

The KWCS sample was taken from the Population and Housing Census conducted in 2010. To ensure the sample was representative of the economically active population, we excluded students, housewives, the unemployed and the retired. The sampling method employed a multistage stratified approach using sampling with probability proportional to size. Census districts were selected using probability proportional to size of systematic sampling which reflected the number of households in each census district. Then, 10 households were randomly chosen within the selected census district. Finally, one eligible person was interviewed in the selected household.

The survey weighting was calculated using the information on distribution by region, locality, size, gender, age and occupation. Additionally, the response rate of the interviewees was considered to calculate the weighting of survey data.

\section{Patient and public involvement}

Both in the KWCS and EWCS, participants and the public were not involved in the development of the study design or planning. Participation was voluntary and could be terminated at any time. Study results were not distributed to the participants after the study by the study team. All data were used strictly confidentially and anonymously.

\section{Study variables}

Sociodemographic and behavioural characteristics

Information on age, sex, educational level, income, smoking habits and alcohol drinking was collected through questionnaires. Age was categorised as $15-29,30-39,40-49,50-59$ and 60 or more years of age. Educational level was categorised as middle school (lower secondary) or less, high school (higher secondary), college and university or more (postgraduate education, tertiary education or above). Monthly income was divided into four groups by quartiles. Alcohol consumption was categorised as none, moderate or risky. Risky alcohol consumption was defined as drinking more than seven units of alcohol at one time (binge drinking) or drinking more than 14 units of alcohol per week. Smoking was categorised as non-smokers, ex-smokers or current smokers.

Health was assessed based on the response to the subjective question, How is your health in general? Very poor, Poor or Fair were regarded as self-rated 
poor health, while Very good or Good were regarded as good health.

\section{Occupation and employment}

The question on occupation in the original questionnaire included eight categories which were professional, management, office, sales, service, skilled, semi-skilled, non-skilled, fishery and farming. For analysis, the eight categories were combined into four categories which were management and professional, office worker, sales and service or manual (skilled, semi-skilled, non-skilled and farming and fishery). Employment status was classified by indefinite, fixed-term and temporary in EWCS. However, employment status was classified by regular, temporary and daily contract in KWCS. In the interaction analysis, employment status was combined into two categories (stable employment vs unstable employment). In European Union (EU) countries, indefinite employment was regarded as stable employment, and fixed-term and temporary employment were regard as unstable employment. Similarly, in Korea, regular employment was regarded as stable employment and temporary employment and employment based on daily contract were regard as unstable employment. Perceived risk at work was assessed by the question 'Do you think your health or safety is at risk because of your work?'. 'Yes' was regarded as a perceived risk, and 'No' was regarded as no perceived risk to safety or health.

\section{Statistical analysis}

We analysed the EWCS and KWCS data separately to compare European and Korean participants. General characteristics are presented as means and SD for continuous variables and numbers and prevalence (\%) for categorical variables. Proportions were calculated by occupation and employment status with survey weighting. The prevalence of perceived risk at work and variables regarding safety and health at work were summarised by occupational categories, as they differed by occupation (online supplementary table 1). To estimate the OR, multiple survey logistic analysis was employed. In the model, age, sex, educational level, income, occupation, smoking and alcohol consumption were included as potential confounders.

\section{Relative excess risk due to interaction (RERI) and the ORs}

For the interaction analysis, we initially employed multiple survey logistic analysis including all potentially confounding variables, and the product term between perceived risk at work and employment status in the model. We then estimated the combined effect of perceived risk of safety or health at work and employment status using the linear combination (lincom) command. Finally, we conducted an interaction analysis between perceived risk at work and employment status using 'linear combination of coefficients' (lincom) and 'nonlinear combination of coefficients' (nlcom). RERI and CIs were estimated using the non-linear combination of coefficients, and the ORs and CIs were estimated using the linear combination of coefficients. The commands 'lincom' and 'nlcom' are postestimation commands for estimating the combined effects of multiple variables after regression-based models. These commands can perform interaction analysis based on both additive and multiplicative scales and can estimate CIs. All statistical analyses were conducted using Stata V.13.1 (StataCorp, College Station, Texas, USA). ${ }^{13}$

The RERI is calculated to estimate the interaction between joint exposures based on additive scales.

$$
\begin{aligned}
& \mathrm{RERI}=\mathrm{OR}_{\text {combined exposure to perceived risk at work and unstable employment }} \\
& -\mathrm{OR}_{\text {exposure to only perceived risk at work }}-\mathrm{OR}_{\text {exposure to only unstable employment }}
\end{aligned}
$$

An RERI larger than 0 indicates supra-additivity.

Ratios of ORs estimate the interaction between two combined exposures based on a multiplicative scale and are calculated using the following formula:

$\mathrm{OR}_{\text {combined exposure to perceived risk at work and unstable employment/ }}$
$\left(\mathrm{OR}_{\text {exposure to only perceived risk at work }} \times \mathrm{OR}\right.$ exposure to only unstable employment

Ratios larger than 1 indicate that the joint effect of two exposures is larger than the product of effects of the two separate exposures.

\section{RESULTS}

\section{Characteristics of the study population}

Table 1 shows the general characteristics of employees in Korea and EU countries. In Korea, the percentage of female employees was $41 \%$. About $60 \%$ of participants were in their $30 \mathrm{~s}$ and $40 \mathrm{~s}, 34 \%$ were current smokers and $28 \%$ were risky alcohol consumers. More than half of the participants had finished college and university. Proportion of sales and service workers was $27 \%$, and the proportion of manual workers was $34 \%$. Regarding employment status, $20 \%$ of the employees were temporary and daily workers.

In the EU survey, the proportion of female employees was $46 \%$. More than half (53\%) of the participants of the study population were in their 30 s and 40 s. The EWCS did not investigate smoking and alcohol consumption. More than one-third (36\%) of the study population had finished postsecondary education or tertiary education. Proportion of sales and service workers was $17 \%$, and the proportion of manual workers was $33 \%$. Regarding employment status, $22 \%$ of the employees had fixed-term or temporary employment.

There was a difference in the survey questionnaire between the KWCS and the EWCS regarding the type of employment. This difference might reflect the different labour contract systems in Korea and EU countries. Employment status of the EWCS was categorised by regular, fixed-term or temporary. In contrast, employment 
Table 1 Characteristics of study populations (survey-weighted analysis)

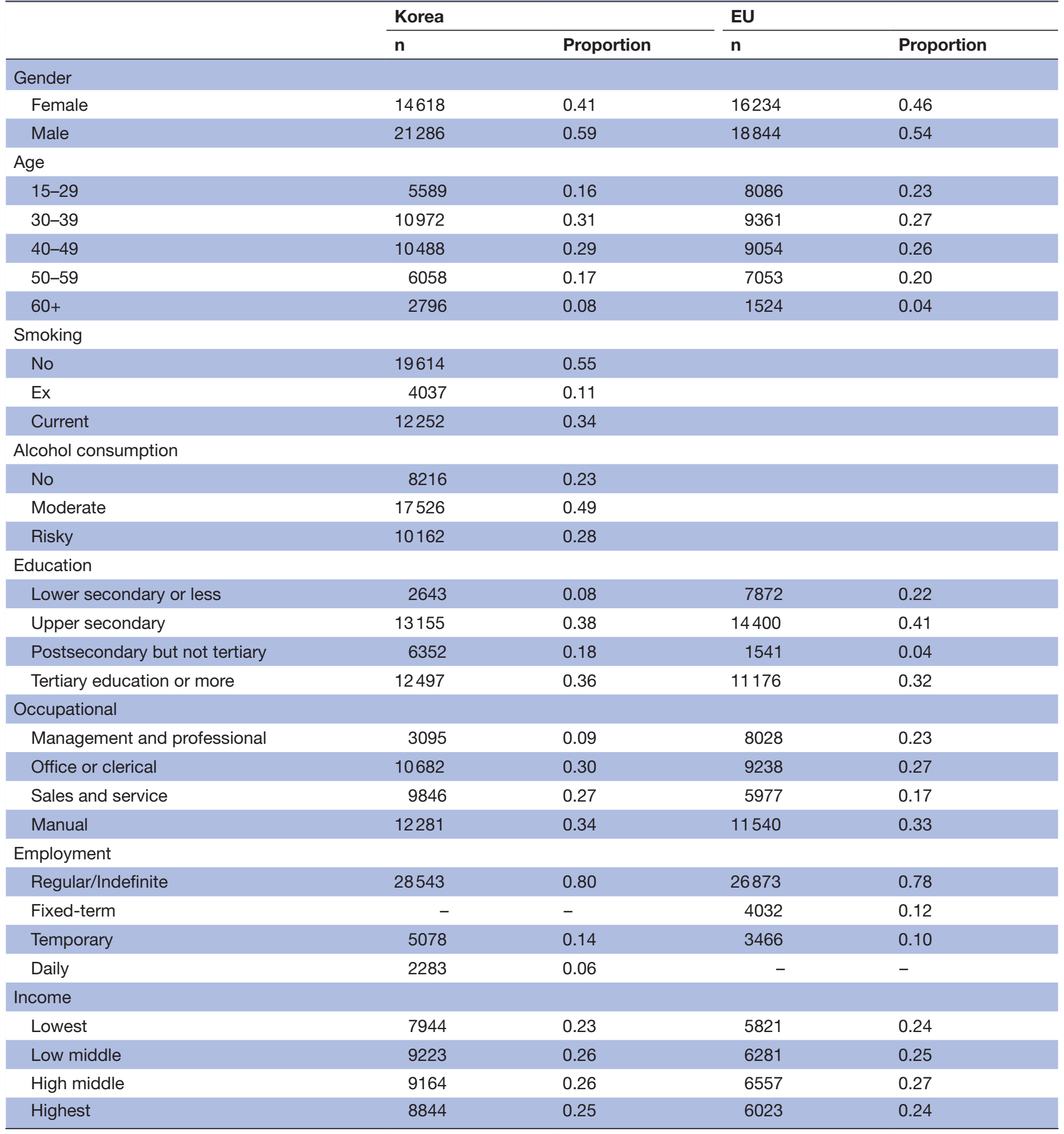

status of the KWCS was classified by regular, temporary or daily. Notably, $6 \%$ of employment in Korea is on a daily contract basis.

Interaction between the perceived risk at work and employment status on self-rated health in Korea and EU countries

In Korea, perceived risk at work (OR: 2.00; $95 \%$ CI: 1.80 to 2.20) and unstable employment (OR: 1.18; 95\% CI: 1.09 to 1.28) both increased the risk of poor self-rated health, with the other factors being constant (table 2). Furthermore, there was a supra-additive interaction between both perceived risk at work and employment status (RERI: 1.03 ; $95 \%$ CI: 0.48 to 1.58 ) and supra-multiplicative interaction (ORs: 1.36 ; $95 \%$ CI: 1.11 to 1.66 ).

In EU countries, only the perceived risk at work (OR: 3.20; $95 \%$ CI: 2.93 to 3.49) was linked to an increase in 
Table 2 Effect of the perceived risk at work and employment status on self-rated health among Korean employees*

\begin{tabular}{|c|c|c|c|}
\hline & \multirow{2}{*}{$\begin{array}{l}\text { No perceived risk at work } \\
\text { OR }(95 \% \mathrm{Cl}): \text { p value }\end{array}$} & \multirow{2}{*}{$\begin{array}{l}\text { Perceive risk at work } \\
\text { OR }(95 \% \mathrm{Cl}): \text { p value }\end{array}$} & \multirow{2}{*}{$\begin{array}{l}\text { OR for perceived risk versus } \\
\text { no perceived risk within strata } \\
\text { of employment } \\
\text { OR }(95 \% \mathrm{Cl}): \mathrm{p} \text { value }\end{array}$} \\
\hline & & & \\
\hline Stable employment† & Reference & 2.00 (1.80 to 2.22): $p<0.001$ & 2.00 (1.80 to 2.20$): p<0.001$ \\
\hline Unstable employment $\ddagger$ & 1.18 (1.09 to 1.28$): p<0.001$ & 3.22 (2.72 to 3.81): $p<0.001$ & 2.72 (2.29 to 3.24): $p<0.001$ \\
\hline $\begin{array}{l}\text { OR for unstable } \\
\text { employment versus stable } \\
\text { employment within strata } \\
\text { of long perceived risk at } \\
\text { work }\end{array}$ & 1.18 (1.09 to 1.28$): p<0.001$ & 1.60 (1.33 to 1.93$): p<0.001$ & \\
\hline
\end{tabular}

Measure of interaction on 1.03 (0.48 to 1.58$)$ : $p<0.001$

additive scale: RERI

Measure of interaction on 1.36 (1.11 to 1.66): $p=0.003$ multiplicative scale: ORs

*Age, gender, income, education, occupations, smoking and alcohol consumption were adjusted in the model.

†Stable employment: regular employment in Korea.

‡Unstable employment: temporary and daily employment in Korea.

RERI, relative excess risk due to interaction.

poor self-rated health, but unstable employment (OR: 1.04; $95 \%$ CI: 0.93 to 1.17 ) was not significantly associated with poor self-rated health (table 3 ). A significant interaction was not found on an additive scale (RERI: 0.18; 95\% CI:-0.36 to 0.71 ), nor on a multiplicative scale (ORs: 1.02 ; $95 \%$ CI: 0.85 to 1.24 ).

\section{DISCUSSION}

The primary purpose of this study was to investigate the interaction between perceived risk at work and employment status in Korea and EU countries. In Korea, both perceived risk at work and employment status were associated with increased proportions of poor self-rated health, and a significant interaction between perceived risk at work and employment status was found both on additive scale and on multiplicative scale. The results indicate that the interaction between perceived risk at work and employment status could have a synergistic detrimental effect on workers' health in Korea. In EU countries, however, an interaction between perceived risk at work and unstable employment was not found.

We previously mentioned the topic of employment conditions in the results, specifically that Korea and EU countries may have different labour contract systems.

Table 3 Effect of the perceived risk and employment status on self-rated health among employees in EU countries*

\begin{tabular}{|c|c|c|c|}
\hline & \multirow{2}{*}{$\begin{array}{l}\text { No perceived risk at work } \\
\text { OR }(95 \% \mathrm{Cl}): \text { p value }\end{array}$} & \multirow{2}{*}{$\begin{array}{l}\text { Perceive risk at work } \\
\text { OR }(95 \% \mathrm{Cl}): \mathrm{p} \text { value }\end{array}$} & \multirow{2}{*}{$\begin{array}{l}\text { OR for perceived risk versus } \\
\text { no perceived risk within } \\
\text { strata of employment } \\
\text { OR }(95 \% \mathrm{Cl}) \text { : p value }\end{array}$} \\
\hline & & & \\
\hline Stable employment† & Reference & 3.20 (2.93 to 3.49): $p<0.001$ & 3.20 (2.93 to 3.49$): p<0.001$ \\
\hline Unstable employmentł & $1.04(0.93$ to 1.17$): p=0.490$ & 3.41 (2.93 to 3.98$): p<0.001$ & 3.28 (2.75 to 3.90$): p<0.001$ \\
\hline $\begin{array}{l}\text { OR for unstable } \\
\text { employment versus stable } \\
\text { employment within strata } \\
\text { of perceived risk at work }\end{array}$ & $1.04(0.93$ to 1.17$): p=0.490$ & 1.07 (0.91 to 1.25$): p=0.405$ & \\
\hline $\begin{array}{l}\text { Measure of interaction on } \\
\text { additive scale: RERI }\end{array}$ & $0.18(-0.36$ to 0.71$): p=0.519$ & & \\
\hline $\begin{array}{l}\text { Measure of interaction on } \\
\text { multiplicative scale: ORs }\end{array}$ & 1.02 (0.85 to 1.24$): p=0.802$ & & \\
\hline
\end{tabular}

${ }^{*}$ Age, gender, income, education and occupations were adjusted in the model. †Stable employment: indefinite employment in EU countries. łUnstable employment: fixed-term and temporary employment in EU countries. EU, European Union; RERI, relative excess risk due to interaction. 
This difference might reflect dissimilarities between the labour market in EU countries and Korea. In Korea, it is more fragmented and divided due to neoliberalisational reform after an International Monetary Fund economic crisis. ${ }^{14}$ Korea also has a lower labour union density and a lower collective agreement coverage rate. ${ }^{1516}$ Evident from our results, a proportion of working population's employment is set on a daily contract basis. The existence of daily employment indicates that there are workers under extremely unstable employment conditions. This unstable employment is not only short term, but is generally precarious. Some of the many aspects of precarious employment include low job security and unfavourable working conditions. ${ }^{17}$

Although the cause of the interaction can be explored through a more detailed investigation of occupational hazard exposure and other social determinants of health, there are two possible explanations for this in Korea. First, there is the possibility that at-risk workers were working under even more dangerous and less healthy working conditions than the quantitative analysis could capture. Another possibility is that precarious workers were more seriously affected by health problems due to harmful social circumstances, such as discrimination and de-unionisation. If the first explanation was the cause of the interaction, working conditions for precarious workers should be improved. If the second was the cause of interaction, socioeconomic inequalities between regular workers and precarious workers should be reduced. Future studies, particularly in Korean, should explore working conditions of workers with unstable employment to identify the causes of the interaction between unstable employment and perceived risk at work.

In both Korea and EU countries, gradients in perceived occupational hazard exposures were observed (online supplementary table 1). There were differences between stable employment and unstable employment in both Korea and EU countries, more significant in Korea. These exposure differences might imply that Korean workers under unstable employment have to bear the heavier burden of hazardous exposure, and reflect the reality that some workplaces do not follow regulations that prohibit subcontracting or outsourcing harmful tasks.

There is increasing concern among the public and researchers about the consequences of unstable employment; several studies in a variety of national and organisational contexts have provided evidence about its negative effect on health. Unstable employment seems more strongly associated with mental health than physical health. A significant amount of literature has demonstrated that workers reporting unstable employment have a higher risk of psychiatric morbidity ${ }^{18-20}$ and suicide. ${ }^{21} 22$ Moreover, previous evidence also suggests that unstable employment may be associated with poor self-rated health. ${ }^{723}$ While some studies have found a significant negative relationship between unstable employment and physical health, there are still uncertainties regarding the intensity of impact, and some studies have found no evidence for a significant relationship between these variables. A meta-analysis of 72 studies suggested that employees with unstable employment generally have poorer mental and physical health. ${ }^{6}$

This study has several methodological shortcomings. First, the cross-sectional nature of the study does not enable the establishment of a causal relationship between exposure and health outcomes. It is possible that people with poor self-rated health tend to have an unstable job, which can lead to an underestimation of actual risk. Second, the measurement of risk at work and health status was subjective which may lead to information bias. In particular, self-rated health is a subjective measurement of health status. However, previous research, including a prospective cohort study, has consistently reported that poor self-rated health is associated to objective health outcomes, such as mortality. ${ }^{25-27}$ After adjusting for other health-related covariates, self-rated health could predict future mortality. Moreover, perceived risk at work reflects a subjective experience and must be self-reported. Therefore, it is challenging to obtain a valid and reliable assessment of risk at work and its subsequent impact on health. Third, self-employed workers were not considered in this study. Self-employment accounts for more than one-fourth of Korea's entire labour force. Self-employed individuals in Korea are concentrated in similar business fields, which results in a higher risk of competition and vulnerability to the influence of the economy. However, this large group of self-employed workers with unstable employment were excluded from our study. Therefore, future studies are required to fully understand this aspect. Finally, we could not identify a specific cause of the negative synergistic effect of unstable employment and perceived risk at work only in Korea. Although discrimination, de-unionisation and insufficient employee protection regulations were suggested as possible causes, these should be supported in empirical studies.

Nonetheless, our sample included a very large number of workers from the general working population, allowing us to study a nonselective population, which has been shown to be crucial. Moreover, as we used representative data from Korea and EU countries, surveyed using almost identical methodologies and survey questionnaires, it was possible to present results of Korea parallel to those of EU.

\section{CONCLUSION}

The results of our study suggest that the combination of both perceived risk at work and unstable employment has a synergistic detrimental effect on workers' health in Korea. To reduce the gap generated by the interaction between perceived risk at work and unstable employment, the cause of these inequalities must be investigated and a specific action plan should be built.

Acknowledgements The authors want to express their appreciation to the Korea Occupational Safety and Health Agency (KOSHA) and Eurofound for offering their 
raw data of the third Korean Working Conditions Survey and fifth European Working Conditions Survey. This article is based on a part of the dissertation titled 'The association between occupational hazard exposures and health inequality among Korean employees,' which was submitted to the Graduate School of Public Health Seoul National University for the degree of Doctor of Philosophy.

Contributors SSC and DP contributed to the conception and design of the study. SSC conducted the statistical analysis. SSC, MYK and DP interpreted the results. SSC contributed to drafting the article. SSC and MYK contributed to revising it after reviewing. MYK and DP discussed the draft. All authors approved the final draft.

Funding This work was supported by the Dong-A University research fund. Competing interests None declared.

Patient consent for publication Not required.

Ethics approval The need for ethical review was waived by the institutional review board of Hallym University Hospital (Approval number: 2017-1050).

Provenance and peer review Not commissioned; externally peer reviewed.

Data availability statement Data are available at the following websites: http:// www.eurofound.europa.eu/working/surveys/for the EWCS and http://www.kosha.or. $\mathrm{kr} / \mathrm{jsp} / \mathrm{kwCs} /$ for the KWCS.

Open access This is an open access article distributed in accordance with the Creative Commons Attribution Non Commercial (CC BY-NC 4.0) license, which permits others to distribute, remix, adapt, build upon this work non-commercially, and license their derivative works on different terms, provided the original work is properly cited, appropriate credit is given, any changes made indicated, and the use is non-commercial. See: http://creativecommons.org/licenses/by-nc/4.0/.

ORCID iD

Mo-Yeol Kang http://orcid.org/0000-0002-1682-865X

\section{REFERENCES}

1 Ministry of employment and labor. Brief report on fatal industrial accidents in the shipbuilding industry; 2017.

2 Son $\mathrm{H}$. The study of the links between contingent workers and industrial accident - using workplace panel survey for analyzing moderation effect of labor union. Seoul National University, The Graduate School of Public Administration, 2016.

3 Benach J, Muntaner C. Precarious employment and health: developing a research agenda. J Epidemiol Community Health 2007;61:276-7.

$4 \mathrm{Kim} \mathrm{M-H,} \mathrm{Kim} \mathrm{C-Y,} \mathrm{Park} \mathrm{J-K,} \mathrm{et} \mathrm{al.} \mathrm{Is} \mathrm{precarious} \mathrm{employment}$ damaging to self-rated health? results of propensity score matching methods, using longitudinal data in South Korea. Soc Sci Med 2008:67:1982-94.

5 Underhill E, Quinlan M. How precarious employment affects health and safety at work: the case of temporary agency workers. Relations Industrielles/Industrial Relations 2011;66:397-421.

6 Sverke M, Hellgren J, Näswall K. No security: a meta-analysis and review of job insecurity and its consequences. J Occup Health Psychol 2002;7:242-64.

7 Rugulies R, Aust B, Burr H, et al. Job insecurity, chances on the labour market and decline in self-rated health in a representative sample of the Danish workforce. J Epidemiol Community Health 2008;62:245-50.
8 Lundberg O, Yngwe Monica Åberg, Stjärne MK, et al. The role of welfare state principles and generosity in social policy programmes for public health: an international comparative study. The Lancet 2008;372:1633-40.

9 Navarro V. The determinants of health policy, a case study: regulating safety and health at the workplace in Sweden. $J$ Health Polit Policy Law 1984:9:137-56.

10 Dragano N, Siegrist J, Wahrendorf M. Welfare regimes, labour policies and unhealthy psychosocial working conditions: a comparative study with 9917 older employees from 12 European countries. J Epidemiol Community Health 2011;65:793-9.

11 Bambra C, Eikemo TA, regimes Wstate. Welfare state regimes, unemployment and health: a comparative study of the relationship between unemployment and self-reported health in 23 European countries. J Epidemiol Community Health 2009;63:92-8.

$12 \mathrm{Kim}$ YS, Rhee KY, Oh MJ, et al. The validity and reliability of the second Korean working conditions survey. Saf Health Work 2013;4:111-6.

$13 \mathrm{Knol}$ MJ, VanderWeele TJ. Recommendations for presenting analyses of effect modification and interaction. Int $J$ Epidemiol 2012;41:514-20.

14 Shin K-Y. Globalisation and the working class in South Korea: Contestation, fragmentation and renewal. J Contemp Asia 2010;40:211-29.

15 Herzer D. Unions and Income Inequality: A Heterogeneous Panel Cointegration and Causality Analysis. Labour 2016;30:318-46.

16 Schauer J. Labor market duality in Korea. . International Monetary Fund, 2018: 18. 1.

17 Julià M, Vanroelen $\mathrm{C}$, Bosmans $\mathrm{K}$, et al. Precarious employment and quality of employment in relation to health and well-being in Europe. Int J Health Serv 2017;47:389-409.

18 Kim S-S, Subramanian S, Sorensen G, et al. Association between change in employment status and new-onset depressive symptoms in South Korea - a gender analysis. Scand J Work Environ Health 2012;38:537-45.

19 Meltzer H, Bebbington P, Brugha T, et al. Job insecurity, socio-economic circumstances and depression. Psychol Med 2010;40:1401-7.

20 Boya FO, Demiral Y, Ergör A, et al. Effects of perceived job insecurity on perceived anxiety and depression in nurses. Ind Health 2008;46:613-9.

21 Kraut A, Walld R. Influence of lack of full-time employment on attempted suicide in Manitoba, Canada. Scand J Work Environ Health 2003;29:15-21.

22 Min K-B, Park S-G, Hwang SH, et al. Precarious employment and the risk of suicidal ideation and suicide attempts. Prev Med 2015;71:72-6.

23 Ferrie JE, Shipley MJ, Stansfeld SA, et al. Effects of chronic job insecurity and change in job security on self reported health, minor psychiatric morbidity, physiological measures, and health related behaviours in British civil servants: the Whitehall II study. J Epidemio Community Health 2002;56:450-4.

24 McDonough P. Job insecurity and health. Int J Health Serv 2000;30:453-76.

25 Mavaddat N, Parker RA, Sanderson S, et al. Relationship of selfrated health with fatal and non-fatal outcomes in cardiovascular disease: a systematic review and meta-analysis. PLoS One 2014;9:e103509.

26 Shen C, Schooling CM, Chan WM, et al. Self-Rated health and mortality in a prospective Chinese elderly cohort study in Hong Kong. Prev Med 2014;67:112-8.

27 Jylhä M. What is self-rated health and why does it predict mortality? towards a unified conceptual model. Soc Sci Med 2009;69:307-16. 